\title{
Comparative analysis of life tables of Bactrocera tau (Diptera: Tephritidae) collected from different geographical regions of North India
}

\author{
Priyanka Thakur*, K.C. Sharma ${ }^{1}$ and Deepali Bakshi ${ }^{2}$ \\ (H.P.), INDIA \\ *Corresponding author. E-mail: thakurento29@gmail.com \\ Received: April 9, 2016; Revised received: February 3, 2017; Accepted: May 4, 2017
}

Department of Entomology, Dr Yashwant Singh Parmar University of Horticulture and Forestry, Nauni, Solan-173 230

\begin{abstract}
The tomato fruitfly, Bactrocera tau (Walker) (Diptera: Tephritidae) is one of the most important pests ofthe family Cucurbitaceae. Toinvestigate local adaptation, we measured the variations in life-histories and life-table parameters among populations from five different geographical regions of North India, Ludhiana (262 mt amsl), Solan (1,502 $\mathrm{mt}$ amsl), Hisar (215 mt amsl), Pantnagar (344 $\mathrm{mt}$ amsl) and Jaach (733 $\mathrm{mt}$ amsl). The principal components analysis showed the life-history and life-table parameters of $B$. tau differed among the five geographical populations. The highest fecundity of 233.20 eggs/female was recorded in the Jaach population and was statistically at par with Hisar (209.21 eggs/female) followed by Solan (202.60 eggs/female), Pantnagar (178.60 eggs/female) and Ludhiana population (105.88 eggs/female). The total developmental period among the five populations of $B$. tau was the longest for the Pantnagar population (16.20 days) followed by Solan (13.90 days), Hisar (12.60 days), Ludhiana (12.30 days) and Jaach (11.60 days). The true intrinsic rate of natural increase $\left(r_{m}\right)$ was $0.120,0.138,0.140,0.116$ and 0.153 for the respective geographical regions while the finite rate of increase $(\lambda)$ was $1.13,1.15,1.15,1.12$ and 1.16 , thus indicating that the fruit fly from Jaach location is more reproductive than the other five geographical regions of North India. Since the study will be useful in knowing the multiplication rate of fruit fly in specific area, accordingly the management practices for this species can be formulated on the bases of these studies. The results thus indicated the geographical variations among different populations of $B$. tau.
\end{abstract}

Keywords: Bactrocera tau , Fruit fly, Geographical regions, Intrinsic rate

\section{INTRODUCTION}

Bactrocera tau (Walker) is a primarypest that damages fruits and vegetables of the family Cucurbitaceae throughout South and Southeast Asia (White and Elson -Harris, 1992).Ithas been reported from almost all parts of Indian subcontinent as a pest on a wide variety of food plants and in certain seasons it causes havoc by completely damaging a number of crops as ithas a wide host range (Narayanan and Batra, 1960). B. tau is not a new speciesbut undoubtedly one of the least investigated. The adults of this species verymuch resemble with $B$. cucurbitae in behavior and biology and were often confused with the latter (Narayanan and Batra, 1960). The similarity in the geographic distribution, host range and damage levels of these species viz. $B$. tau, B. cucurbitae have also been reported from China (Yang et al., 1994).B. tau was reported as a serious pest of cucurbitaceous vegetables (Bhalla and Pawar, 1977;Kashyap and Hameed, 1981) and of solanaceous fruits like tomato (Gupta, 1989; Ranganath and Veena kumari, 1996).

During recent years, the area under commercial cultivation of cucurbitaceous vegetables has gradually in- creased. The attack of fruit fly is a major constraint in profitable farming of cucurbits (Chaudhary and Patel, 2007).The knowledge of biology of insect pests is helpful indeveloping efficient management strategy that will prevent wasteful use of costly as well as hazardous chemicals. It tells about the developmental stages, their duration, time of occurrence and the time of infestation, etc. (Huang and Chi., 2012; Laskar, 2013; Mir et al., 2014 and Melinand et al., 2016). Keeping in view these facts, the present study aims at finding the relative variations in the biological parameters of five populations of this pest collected from different geographical regions of North India of different altitudes..

\section{MATERIALS AND METHODS}

Sampling locations: The infested fruits with B.tau were collected manually in the year 2014-2015 from farmers fields from five different geographical regions of North India of different altitudes (Table 1).

Maintenance of the culture of Bactrocera tau: The laboratory culture of $B$. tau was raised from infestedfruits of tomato and cucurbits collected from different locations in specially designed fruit fly rearing cages measuring $90 \mathrm{~cm} \times 45 \mathrm{~cm} \times 45 \mathrm{~cm}$, at room tempera- 
ture. A removable tray was fitted at the base of the cage filled with a mixture of sterile fine sand and saw dust upto $30 \mathrm{~cm}$ height for pupation. The adults were providedwith their natural hosts for oviposition as well as a mixture of dry glucose and protein hydrolysate (Protinex ${ }^{\circledR}$, Pfizer Ltd.) in the ratio of 1:1 as per Gupta (1989)in a petri-plate for feeding, and the diet was changed daily. The flies were also provided with water soaked cotton swabs in a $20 \mathrm{ml}$ plastic vial filled with water. Plastic cups filled with water were placed below the legs of cages to avoid themenace of ants.

Table 1. Sampling localities of Bactrocera tau.

\begin{tabular}{llc}
\hline Locality & \multicolumn{1}{c}{ State } & $\begin{array}{c}\text { Altitude (m) } \\
\text { amsl }\end{array}$ \\
\hline Ludhiana & Punjab & 262 \\
Solan & Himachal Pradesh & 1,502 \\
Hisar & Haryana & 215 \\
Pantnagar & Uttarakhand & 344 \\
Jaach & Himachal Pradesh & 733 \\
\hline
\end{tabular}

Geographical variation and reproductive biology: The studies on variations among population of the fruit fly, B. tau collected from five different geographical regions of North India were carried outby studying the life fertility tables. The eggs of the fruit fly were obtained from the laboratory culture and were used for studying the life tables. The life tables were prepared as per the observations made on the duration of preoviposition period, post-oviposition periods, adult longevity and age specific fecundity. The intrinsicrate of increase $\left(\mathrm{r}_{\mathrm{m}}\right)$, mean generation time $(\mathrm{T})$, finite rate increase $(\lambda)$, doubling time (DT) and net reproductive rate $\left(R_{0}\right)$ were assessed using method of Brich (1948) and elaborated by Howe (1953) and Carey (1993).

\section{RESULTS AND DISCUSSION}

The total developmental period among the five populations of $B$. tau was the longest for the Pantnagar population (16.20 days) followed by Solan (13.90 days), Hisar (12.60 days), Ludhiana (12.30 days) and Jaach (11.60 days). There was no significant difference in the pre-oviposition period and post-oviposition period among all the five populations. The oviposition period of the Jaach and Solan population were statistically at par but differed from Hisar, Pantnagar and Ludhiana population. It was observed that the highest fecundity of 233.20 eggs/female was recorded in the Jaachpopulation and was statistically at par with the Hisar population (209.21 eggs/female) followed by Solan (202.60 eggs/ female), Pantnagar (178.60 eggs/female)and Ludhiana population (105.88 eggs/female). The minimum fecundity of 105.88 eggs/female was recorded for the Ludhiana population (Table 2 ).

The results showed significant variations in developmental period of $B$. tau among population of different

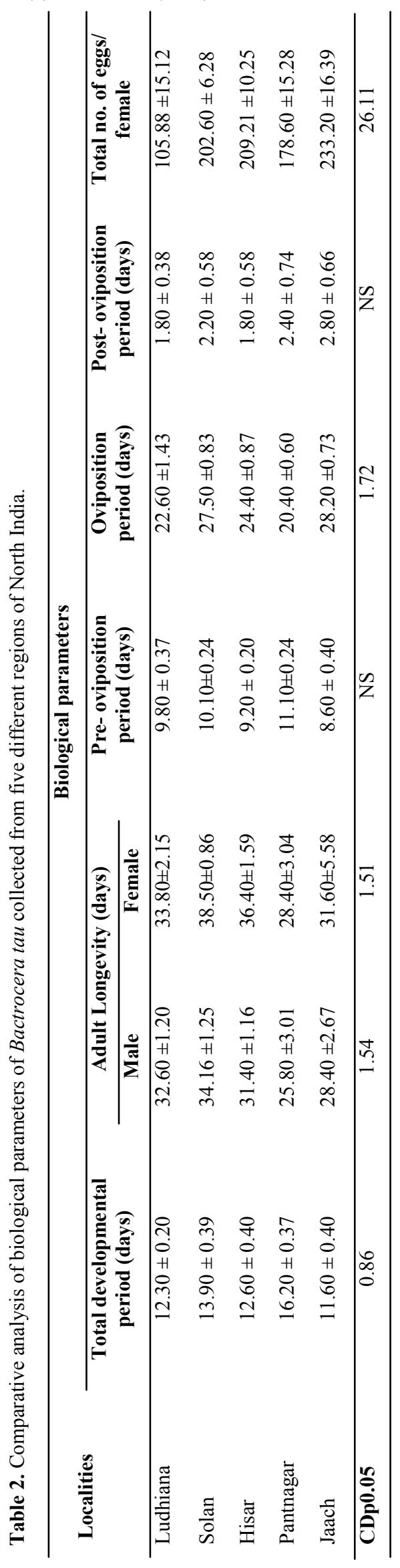


Priyanka Thakur et al. / J. Appl. \& Nat. Sci. 9 (2): 998- 1001 (2017)

Table 3. Fertility parameters of Bactrocera tau collected from five different regions of North India.

\begin{tabular}{|c|c|c|c|c|c|}
\hline Fertility parameters & Ludhiana & Solan & Hisar & Pantnagar & Jaach \\
\hline Gross reproductive rate $(\mathrm{GRR})(\Sigma(\mathrm{mx}))$ & 65.16 & 118.50 & 125.53 & 95.36 & 143.54 \\
\hline $\begin{array}{l}\text { Net reproductive rate (female eggs/female) }\left(\mathrm{R}_{\mathrm{o}}\right)(\Sigma \\
(\operatorname{lxmx}))\end{array}$ & 35.68 & 67.25 & 68.84 & 47.10 & 79.11 \\
\hline $\begin{array}{l}\text { Approximate generation time }\left(\mathrm{T}_{\mathrm{c}}\right)\left(\Sigma(\mathrm{xlx} \mathrm{mx}) /\left(\mathrm{R}_{0}\right)\right. \\
\text { (days) }\end{array}$ & 31.38 & 32.63 & 32.21 & 34.09 & 31.46 \\
\hline $\begin{array}{l}\text { Innate capacity for natural increase }\left(r_{c}\right) \\
\left(\log \text { e } R_{o} / T_{c}\right)\end{array}$ & 0.113 & 0.128 & 0.131 & 0.113 & 0.138 \\
\hline $\begin{array}{l}\text { True intrinsic rate of increase(female/female/day) } \\
\left(\mathrm{r}_{\mathrm{m}}\right)\end{array}$ & 0.12 & 0.138 & 0.14 & 0.116 & 0.153 \\
\hline True generation time $(T)\left(\log R_{o} / r_{m}\right)$ (days) & 29.78 & 30.06 & 30.23 & 33.20 & 28.56 \\
\hline Finite rate of natural increase $(\lambda)\left(\right.$ Antilog e $\left.r_{m}\right)$ & 1.13 & 1.15 & 1.15 & 1.12 & 1.16 \\
\hline Doubling time $(\mathrm{DT})\left(\log \mathrm{e}^{2} / \mathrm{r}_{\mathrm{m}}\right)$ (days) & 7.23 & 6.20 & 6.20 & 7.48 & 5.67 \\
\hline Weekly multiplication of population $\left(\mathrm{W}_{\mathrm{m}}\right)\left(\mathrm{e}^{7} \mathrm{r}_{\mathrm{m}}\right)$ & 2.32 & 2.63 & 2.66 & 2.25 & 2.92 \\
\hline
\end{tabular}

locations and are in agreement with those of Singh et al. (2010), who reported that the duration of B. tau from egg to adult was completed in 14.2+or-1.69 days and the longevity of mated females and males was 130.33and 104.66days, respectively. Similar results were reported by Mir et al. (2014) on melon fruit fly, B.cucurbitae who reported that the duration of egg, larval, pre-pupal and pupal periods were 16.8 hours, and 4.5, 0.8 and 8.4days, respectively. Pre-oviposition and oviposition periods ranged from 10-15 and 1228 days. Fecundity varied from 58-92 eggs, while egg viability was $86.1 \pm 0.54$. Sex ratio (male:female) was $1.10 \pm 0.14$.Melinand et al. (2016) studied the duration ofthe life cycle of $B$. dorsalis and found that it was shorter than $C$. cosyra.The number of eggs laid by the female of $B$. dorsalis (269 in the south, 347 in the cen-

ter and north) was higher than this of the female of $C$. Cosyra(186 in thesouth, 196 in the center, 197 in the north).

Fertility tables: Fertility table summarizes the informationon the biological performance of a species. The present studies on the fertility parameters reveal that the mean female progeny per female over the entire reproductive period for Ludhiana, Solan, Hisar, Pantnagar and Jaachpopulationwas 65.16, 118.50, 125.53, 95.36 and 143.54 days, respectively on cucumber whereas the net reproductive rate $\left(\mathrm{R}_{\mathrm{o}}\right)$ which takes into consideration the age- specific survival of the fruit flywas $35.68,67.25,68.84,47.10$ and 79.11 while the true generation time $(\mathrm{T})$ was $29.78,30.06,30.23,33.20$ and 28.56 days. The true intrinsic rate of natural increase $\left(r_{m}\right)$ for the population of fruit collected from

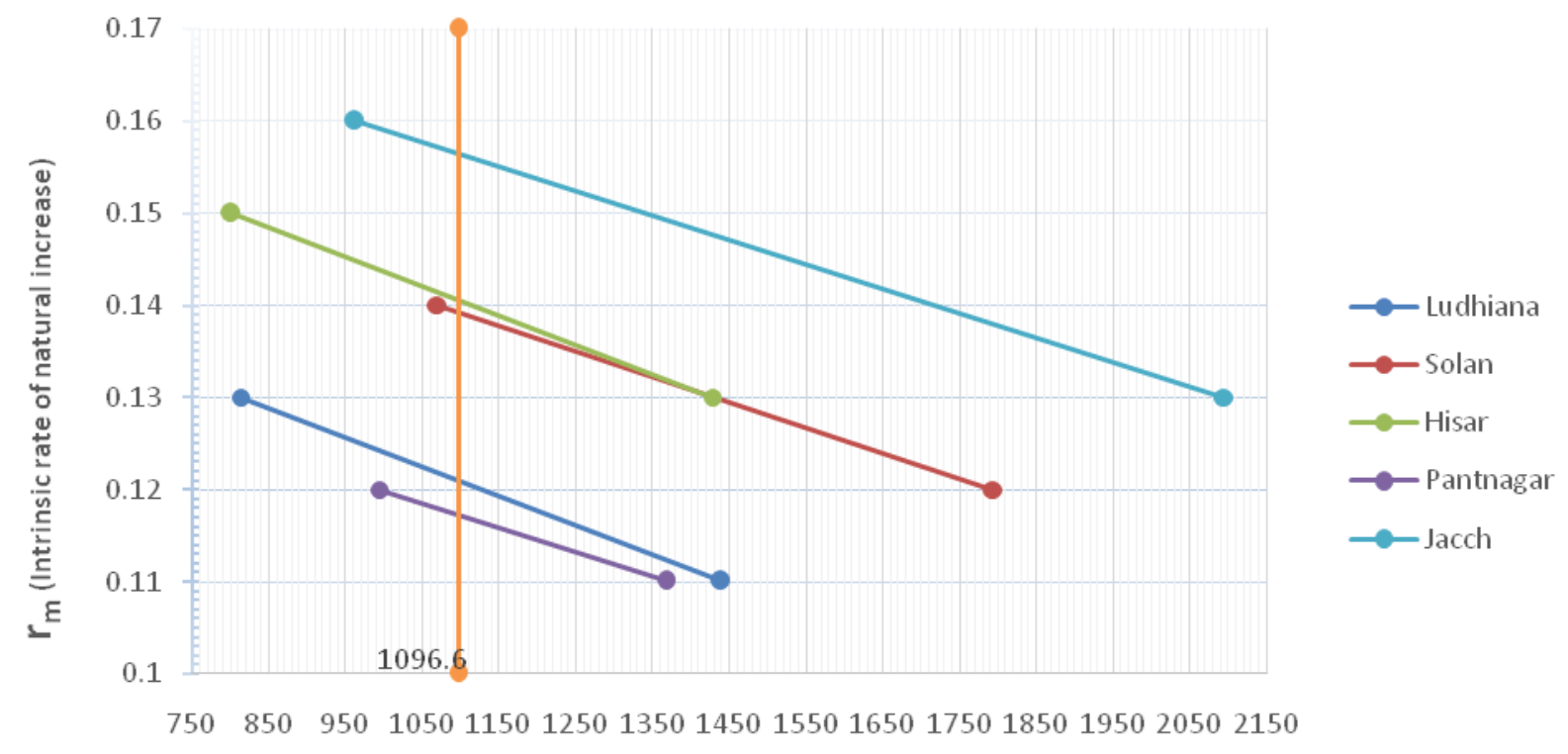

$$
\sum \mathrm{e}^{(7-\mathrm{rmx})} \mid \mathrm{x} \mathrm{mx} \text { (Trial } \mathrm{r}_{\mathrm{m}} \text { ) }
$$

Fig. 1. True intrinsic rate of increase $\left(r_{m}\right)$ of Bactrocera tau collected from five different regions of North India. 
Ludhiana, Solan, Hisar, Pantnagar and Jaachwas $0.120,0.138,0.140,0.116$ and 0.153 female eggs/ female and the finite rate of increase $(\lambda)$ was 1.13 , $1.15,1.15,1.12$ and 1.16 , respectively indicating a marked variation in the intrinsic rate of natural increase (Table 3).

Huang and Chi (2011)reportedthat at $25^{\circ} \mathrm{C}$ the intrinsic rate of increase ( $\mathrm{r}$ ) forthe two different population was 0.1354 and 0.1002 per day while the net reproductive rate $\left(\mathrm{R}_{0}\right)$ was 206.3 and 66.0 offspring, respectively. Zart et al., (2010) studied the biology and fertility life table of the South American fruit fly, Anastrepha fraterculus on grape and observed that the net reproductive rate $\left(R_{0}\right)$ and finite rate of increase $(\lambda)$ were 1.71 and 1.01, respectively.Populations of tephritids from different geographical regions may differ in various reproductive and life history traits (Dimantidis et al., 2011). Tanga et al. (2015) demonstrated that Ceratitis rosa R1 and C. Rosa R2 from Kenya and South Africa were physiologically distinct in their response to different temperature regimes thus supports the existence of two genetically distinct populations of $C$. rosa. The difference in the life table characteristics of different populations may also be attributed to the inherent genetic variations in the different geographical populations of B. tau.

\section{Conclusion}

The results presented here indicate thatgeographic variation in life table characteristics exists among the populations of $B$. tau. As with other attributes, these variations can best be explained as responses to natural and also artificial election. There was a marked variation in the intrinsic rate of natural increase $\left(\mathrm{r}_{\mathrm{m}}\right)$ among the five populations of the North India. The highest was observed in the Jaach population thus indicating that the fruit fly from this location is more reproductive than the other five geographical regions of North India.

\section{REFERENCES}

Bhalla, O. P. and Pawar, A. D. (1977). A survey study of insect and non-insect pests ofeconomic importance in Himachal Pradesh. Tiku and TikuKitabMahal,Bombay, $80 \mathrm{pp}$

Brich, S. (1948). The intrinsic rate of natural increase in insectpopulation. Journal of Animal Ecology, 17: 15-26

Carey, J. R. (1993). Applied demography for biologist withspecial emphasis on insects. Oxford University Press,New York.206 p.

Chaudhary, F. K. and Patel, G. M. (2007). Ovipositional preference of melon fly, B.cucurbitaeCoquilett in its cultivated hosts. Insect Environment, 13(3): 135-137

Dimantidis, A. D., Carey, J. R., Nakas, C. T. and Papadopoulos, N. T. (2011). Ancestral populations perform better in a novel environment: Domestication of Mediterranean fruit fly populations from five global regions. Biological Journal of the Linnean Society, 102:334-345
Gupta,Divender. (1989). Population dynamics of some commonly occurring Tephritidae in Himachal Pradesh. Ph. D Thesis, Dr. Y. S. ParmarUniversityof Horticulture and Forestry, Nauni, Solan (H. P.), 293p.

Howe, R. W. (1953). The rapid determination of intrinsic rateof increase of an insect population. Annals of $\mathrm{Ap}$ pliedBiology, 40:134-155

Huang, Y. and Chi, H. (2012). Life tables of Bactroceracucurbitae (Diptera: Tephritidae): with an invalidation of the jackknife technique. Journal of Applied Entomology. DOI: $10.1111 /$ jen.12002

Huang, Y. B. and Chi, H. (2011). Age-stage, two-sex life tables of Bactroceracucurbitae (Coquillett) (Diptera: Tephritidae) with a discussion on the problem of applying female age-specific life tables to insect populations. Insect Science, 8: 1-11

Kashyap, N. P. and Hameed, S. F. (1981). Residue of some organo phosphorous insecticides on/in peach fruits. $\mathrm{Hi}$ machal Journal of Agriculture Research, 7:46-47

Laskar, N. (2013). Biology and biometrics of melon fruit fly, Bactrocera cucurbitae (Coq.) on bitter gourd, Momordicacharantia L. and pumpkin, Cucurbita pepo L. Current Biotica, 7(1-2): 51-59

Mir, S. H., Dar, S. A., Mir, G. M. and Ahmad, S. B. (2014). Biology of Bactroceracucurbitae(Diptera: Tephritidae) on cucumber. Florida Entomologist,97(2):753-758

Melinand, N. E. N., Nondenot, A. L. R., Bertille, K. E. A. A., Christian, T. D. K., Adagba,O.andPhilomene, S. K. B.(2016). Comparative study of some parameters biological of BactroceradorsalisandCeratitiscosyra(Diptera: Tephritidae) pests of mango (Mangiferaindica) in Côte d'Ivoire. Journal of Advances in Biology, 9(3): 18871895

Narayanan, E. S. and Batra, H. N. (1960). Fruit flies and their Control. Indian Council of Agricultural Research, New Delhi, P. 68

Ranganath, H. R. and Veenakumari, K. (1996). Tomato (Lycopersicon esculentum Miller): a confirmed host of the melon fly, Bactrocera (Zeugodacus) cucurbitae Coquillett. Insect Environment, 2: 3

Singh, S. K., Kumar, D. and Ramamurthy, V. V. (2010). Biology of Bactrocera (Zeugodacus) tau (Walker) (Diptera: Tephritidae). Entomological Research, 40(5): 259-263

Tanga, C. M., Manrakhan, A., Daneel, J. H., Mohamed, S. A., Fathiya, K. and Ekesi, S. (2015).Comparative analysis of development and survival of two Natal fruit fly Ceratitis rosa Karsch (Diptera, Tephritidae) populations from Kenya and South Africa. Zookeys, 540: 467-487

White, I. and Elson- Harris, M. M. (1992). Fruit flies of economic significance: their identification and bionomics. Commonwealth Agriculture Bureau International, Oxon, UK, $601 \mathrm{p}$

Yang, P. J., Carey, J. R. and Dowell, R. V. (1994). Tephritid fruit flies in China: Historical background and current status. Pan-Pacific Entomologist,70:159-167

Zart, M., Fernandes, O. A. and Botton, M. (2010).Biology and fertility life table of the South American fruit fly Anastrephafraterculus on grape. Bulletin of Insectology.63(2): 237-242 